\title{
Kreativitas Pembelajaran Melalui Communication Skill dalam Masa Pandemi COVID-19 Oleh Guru TK Di Kecamatan Sawangan, Kotamadya Depok
}

\author{
Iis Mariam¹, Nining Latianingsih ${ }^{2}$, Titik Purwinarti ${ }^{3}$, Endah Wartiningsih ${ }^{4}$, \\ Muhammad Zaenal Abidin Eko Putro ${ }^{5}$ \\ Politeknik Negeri Jakarta, \\ Jl. Professor Doktor G.A. Siwabessy, Kukusan, Kecamatan Beji, Kampus Baru UI Depok ${ }^{1,2,3,4,5}$ \\ Email: iis.mariam@bisnis.pnj.ac.id ${ }^{1}$
}

\begin{abstract}
ABSTRAK
Dalam masa pandemic COVID-19 saat ini merujuk pada kebijakan Mendikbud untuk penyelenggaraan kegiatan pembelajaran masih tetap menggunakan school from home $(\mathrm{SCH})$ mulai dari tingkat pendidikan dasar sampai pada perguruan tinggi mengakbiatkan perubahan dalam system penyelenggaraan pembelajaran. Pola pendidikan dan pengajaran pada tingkat pendidikan anak usia dini (PAUD) dan Taman Kanak-Kanak (TK) mengalami perubahan dalam aspek strategi dan media pembelajaran dari para guru kepada siswa, sehingga pola belajar harus dibuat sedemikian rupa agar tetap memberikan rasa nyaman, menyenangkan dan sesuai dengan tujuan pembelajaran di sekolah TK di Kotamadya Depok. Kendala yang ditemukan dalam proses pembelajaran ini adalah media teknologi informasi serta bentuk komunikasi yang tetap mudah dan menarik untuk disampaikan kepada siswa yang tetap belajar di rumah. Masalah dalam pengabdian ini adalah bagaimana pemanfaatan media teknologi informasi sebagai media pembelajaran yang dapat diakses dengan mudah oleh siswa di rumah, serta perlu peningkatan keterampilan komunikasi para guru TK dalam pembelajaran. Dalam pengabdian kepada masyarakat ini ada dua mitra yang terlibat, yaitu: TK Islam Al Yazid dan TK Aisyiah Bustanul Atfhal 14, Sawangan, Depok. Metode yang digunakan dalam pengabdian kepada masyarakat ini adalah pelatihan dan pendampingan kepada peserta, dengan metode diskusi, tanya jawab dan latihan. Hasil dari pengabdian kepada masyarakat ini adalah peserta telah mampu menggunakan media pembelajaran online seperti zoom meeting, whats app, menyampaikan materi dengan menarik, memparaktekkan komunikasi secara interaktif sehingga proses belajar mengajar secara online oleh guru tetap memberikan rasa nyaman, kreatif dan menyenangkan siswa.
\end{abstract}

Kata kunci: Etika; Komunikasi Organisasi; Media Pembelajaran

\begin{abstract}
In the current COVID-19 pandemic, referring to the Ministry of Education and Culture's policy for implementing learning activities and learning delivery system still using school from home (SCH) that applies from the basic education level to tertiary institutions. Education and teaching patterns at the early childhood education (PAUD) and Kindergarten (TK) levels have changed in the aspects of strategies and learning media from teachers to students and impact of this situation is patterns must be made in such a way of teaching and learning provide a sense of comfort, fun and creative to fulfill the learning objectives in kindergarten schools in Depok Municipality. The constraints found in this learning process are information technology media and forms of communication that remain easy and interesting to convey to students who are still studying at home. The problem in this service is how to use information technology media as a learning strategy that can be accessed easily by students at home, and also need to improve the communication skills of kindergarten teachers in learning. In this community service there are two partners involved, such as: TK Islam Al Yazid and TK Aisyiah Bustanul Atfhal 14, both of two schools located in Sawangan, Depok. The method used in this community service is training and mentoring to participants, with methods of discussion, question and answer and exercises. The result of this community service is that
\end{abstract}


participants have been able to use online learning media such as zoom meetings, whats app, to delivery all the material attractively, practice interactive communication, so that the online teaching and learning process by the teacher still provides a sense of comfort, creativity and fun for students.

Keywords: Ethics; Organization Communication; Media Of Learning

\section{PENDAHULUAN}

Dalam masa COVID-19 saat ini pendidikan di Indonesia dilakukan secara online dimulai pada pendidikan tingkat dasar, menengah sampai perguruan tinggi. Pendidikan yang dilakukan saat ini terutama untuk pendidikan anak usia dini termasuk Taman KanakKanak menjadi pertimbangan untuk pembelajaran dilaksanakan tidak secara tatap muka sesuai dengan arahan kebijakan dari pemerintah agar pembelajaran dilakukan secara online, dan apabila ada jadwal kunjungan ke rumah siswa harus tetap mengacu pada aturan protokol kesehatan. Merujuk pada data dinas Dikbud Kotamadya Depok untuk tahun ajaran 2020/2021 jumlah sekolah TK dan KB TA 2020-2021 Kotamadya Depok, untuk Taman Kanak Kanak (TK) berjumlah 6 untuk negeri, 496 untuk swasta. Sementara untuk Taman Bermain (KB) ada 386 dari swasta. untuk TK yang ada di wilayah kecamatan Sawangan, Depok berjumlah 37 sekolah (Kemendikbud, 2020). Dua dari TK yang ada di kecamatan Sawangan, Depok tersebut menjadi mitra dalam pengabdian kepada masyarakat tahun 2020, yaitu: TK Islam Al Yazid, Jl. Abdul Wahab, Perumahan Telaga Jambu Blok G/16, RT.07/RW.04, Sawangan Baru, Depok dan TK Aisyiyah Bustanul Atfhal 14, Jl. H.Maksum No.44, Sawangan, Depok.

Masalah yang ditemukan dari kedua mitra dapat dilihat dari Analisis SWOT Permasalahan Mitra, untuk analisis kekuatan (i) Tersedianya suatu komitmen dari pemerintah daerah serta masyarakat dalam penyelenggaraan pendidikan PAUD; (ii) Adanya rekrutmen guru Taman Kanak Kanak dengan kualitas sumber daya yang kompeten dari hard skill dan soft skill; (iii) Kualitas Guru TK saat ini memiliki latar belakang pendidikan minimal sarjana (PAUD) dan disiplin keilmuan lainnya; (iv) Model pembelajaran menggunakan media online pada saat pandemi COVID-19 direspon dengan cepat oleh Guru TK. Analisis kelemahan (i) Kemampuan staf administrasi dan guru TK dalam menginput data untuk laporan dapodik dan borang akreditasi berbasis computer masih kurang; (ii) Tuntutan terhadap kompetensi guru TK dalam proses belajar mengajar masih perlu ditingkatkan terutama dalam menyajikan materi berbasis online; (iii) Keterampilan berkomunikasi pada saat proses belaja mengajar secara online masih perlu ditingkatkan. Analisis peluang (i) Tingginya dukungan pemerintah serta partisipasi 
masyarakat dalam penyelenggaraan dan kontirubusi biaya pendidikan dasar yang berkualitas dan terjangkau; (ii) Munculnya perumahan baru dengan konsep cluster di Sawangan dengan komposisi jumlah keluarga muda; (iii) Lokasi sekolah yang relatif mudah dari jalan Propinsi dan akses jalan desa, dan (iv) Daerah Sawangan memiliki destinasi wisata alam yang baru, tempat kuliner menarik serta adanya pusat perbelanjaan yang berkonsep mewah. Analisis ancaman (i) Perubahan kebijakan pemerintah mengenai kompetensi guru; (ii) Adanya perubahan metode dalam proses pendidikan dan pengajaran berbasis online pada masa COVID-19 harus direspon cepat oleh para guru; (iii) Munculnya program pendidikan untuk TK swasta yang menawarkan sistem pembelajaran yang unik dan kreatif; (iv) Pendidikan guru TK yang harus memiliki latar belakang pendidikan program Sarjana; (v) Kemampuan guru TK di sekolah yang memberikan kegiatan co-kurikuler kepada siswa dalam berbahasa inggris.

Masalah utama dari kedua TK tersebut adalah proses pembelajaran dalam masa COVID-19 masih perlu ditingkatkan dan media belajar perlu lebih kreatif, inovatif. Tujuan dan manfaat dari pengabdian ini adalah terwujudnya strategi dan media belajar yang kreatif, inovatif, serta menyenangkan untuk siswa serta Guru dapat menggunakan keterampilan komunikasi yang dapat dimengerti dan diterima baik oleh siswa Taman Kanak- Kanak (TK).

Komunikasi memiliki pengertian dimana proses individu mengirimkan stimulus yang biasanya dalam bentuk verbal untuk mengubah tingkah laku orang lain. Hal ini dapat diartikan bahwa komunikasi sebagai sebuah proses (aktifitas) bukan sebagai suatu benda mati (Arni, 2015). Menurut Effendy (2015) strategi dalam komunikasi harus dihubungkan dengan komponen-komponen mengenai pesan apa yang dinyatakan, media apa yang digunakan, siapa komunikan dan komunikatornya. Strategi di dalam proses pembelajaran merupakan salah satu factor penting yang secara konsisten harus terus menerus dipromosikan dalam pembelajaran mandiri di kelas. Penelitian lain menghasilkan adanya guru dan siswa sebagai factor eksternal yang dapat mempengaruhi dalam proses pembelajaran mandiri. Kontribusi hasil penelitian lainnya mengenai pembelajaran mandiri adalah saling memahami aktivitas guru di dalam kelas dan menghasilkan strategi dalam pembelajaran (Kistner, et.al, 2015). Menurut Fatkhurrokhman (2018: 169-170) penelitian strategi pembelajaran untuk menghasilkan pembelajaran yang produktif yaitu: adanya perencanaan (plan), kegiatan (action) dan hasil (results). Pinter (2011) mengelompokkan peserta pembelajaran pada tiga kelompok usia muda (young learner) ada tiga, yaitu: prasekolah (usia 3-5 tahun), sekolah dasar (6-12 tahun) dan menengah (11-12 tahun). 
Strategi dan media pengajaran yang digunakan pada ketiga tingkatan usia tersebut berbeda, terlebih pada pendidikan tingkat pra-sekolah (Kelompok Bermain dan Taman Kanak-Kanak). Guru sebelum memberikan pengajaran telah melakukan persiapan media apa yang akan digunakan dalam proses belajar dan materi apa yang sesuai dengan usia siswa (Sukmahidayanti, 2015). Adapun media pembelajaran adalah sarana atau media terjadinya proses belajar mengajar (Daryanto, 2009: 419). Menurut Gerald dan Ely dalam Arsyad (2014) bahwa media apabila dipahami secara garis besar adalah manusia, materi atau kejadian yang membangun kondisi yang membuat siswa mampu memperoleh pengetahuan, ketarampilan atau sikap, sehingga dapat merangsang pikiran, perasaan serta perhatian dan minat siswa.

\section{METODE}

Metode yang digunakan dalam pengabdian kepada masyarakat ini adalah metode deskriptif untuk menjelaskan hasil pelatihan dan pendampingan dari Tim pengabdian kepada masyarakat Berbasis Dosen/Kelompok Bidang Keahlian Jurusan Administrasi Niaga-PNJ yang dilakukan di TK Islam Al Yazid serta TK Aisyiah Bustanul Atfhal 14, Sawangan, Depok. Adapun teknik pengumpulan data dilakukan melalui studi dokumentasi mengenai data pendidikan PAUD di wilayah Depok, data program pendidikan di TK Islam Al Yazid serta TK Aisyiah Bustanul Atfhal 14, Sawangan, Depok, studi literature mengenai komunikasi dan pembelajaran online dalam masa COVID-19, serta wawancara dengan Ketua Ikatan Guru TK (IGTK) Depok dan Kepala Sekolah dari dua TK yang menjadi objek tempat pengabdian kepada masyarakat.

Objek yang terlibat dalam pelaksanaan pengabdian kepada masyarakat ini ada 20 orang yang terdiri dari seluruh Guru TK dan Kepala Sekolah dari TK Islam Al Yazid dan TK Aisyiah Bustanul Atfhal 14, Sawangan, Depok serta anggota dan ketua dari Ikatan Guru TK (IGTK) Depok.

\section{HASIL, PEMBAHASAN DAN DAMPAK}

Kegiatan pengabdian kepada masyarakat dilaksanakan pada tanggal 6 Agustus 2020 oleh Tim dosen sebagai instruktur dan mahasiswa PNJ. Pengabdian kepada masyarakat ini merupakan kegaitan kelompok bidang keahlian/dosen dari lintas program studi yang ada di PNJ, dan Tim terdiri dari: program studi D3 Administrasi Bisnis, D4 
Administrasi Bisnis Terapan, D4 Desain Grafis serta instruktur praktisi dari bidang teknologi informasi.

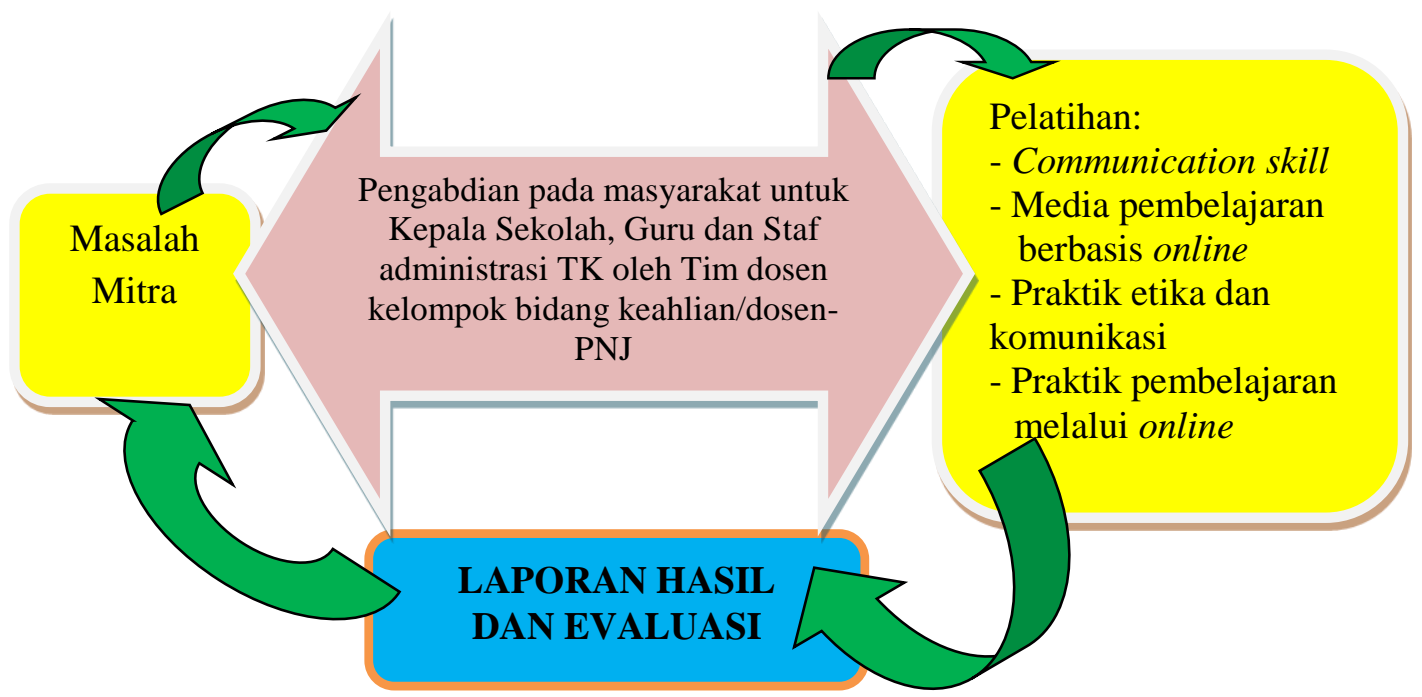

Gambar 1 Diagram Proses Kegiatan Pengabdian Kegiatan Masyarakat Sumber: data diolah, 2020

Metode yang dilaksanakan dalam pengabdian kepada masyarakat ini adalah dengan memberikan pelatihan kepada para guru dan kepala sekolah dengan mempertimbangkan protokol kesehatan di era COVID-19 yaitu mencuci tangan, tetap menjaga jarak, menggunakan masker serta dilakukan pengecekan suhu tubuh sebelum kegiatan dimulai. Adapun proses dan hasil dari pelatihan yang diberikan kepada peserta oleh Tim Instruktur dari PNJ dan Praktisi teknologi informasi dapat dilihat pada tabel 1.

Tabel. 1 Materi dan Hasil Pelatihan

\begin{tabular}{|c|c|c|c|}
\hline No & Materi & Indikator Kegiatan & Hasil Pelatihan \\
\hline 1 & $\begin{array}{l}\text { Keterampilan } \\
\text { berkomunikasi }\end{array}$ & $\begin{array}{l}\text { a. Pengertian } \\
\text { komunikasi } \\
\text { b. Jenis Komunikasi } \\
\text { c. Paradigma } \\
\text { komunikasi } \\
\text { menurut Laswell }\end{array}$ & $\begin{array}{l}\text { a. Peserta telah mampu menjelaskan } \\
\text { pengertian komunikasi baik verbal } \\
\text { dan non verbal; } \\
\text { b. Peserta telah mampu menjelaskan } \\
\text { jenis komunikasi yang digunakan } \\
\text { dalam proses pembelajaran dengan } \\
\text { benar; } \\
\text { c. Peserta telah mampu menyebutkan } \\
\text { paradigm komunikasi menurut } \\
\text { Laswell, yaitu: sender, decode, } \\
\text { message, media dan feedback } \\
\text { dengan benar. }\end{array}$ \\
\hline 2 & $\begin{array}{l}\text { Media } \\
\text { Pembelajaran }\end{array}$ & $\begin{array}{l}\text { Jenis media yang } \\
\text { digunakan dalam } \\
\text { pembelajaran } \\
\text { tatap muka dan } \\
\text { online }\end{array}$ & $\begin{array}{l}\text { a. Peserta telah mampu menjelaskan } \\
\text { mengeni jenis media pembelajaran } \\
\text { yang tepat digunakan kepada siswa } \\
\text { pada masa COVID-19 dengan } \\
\text { benar; }\end{array}$ \\
\hline
\end{tabular}




\begin{tabular}{|c|c|c|c|}
\hline No & Materi & Indikator Kegiatan & Hasil Pelatihan \\
\hline 3 & $\begin{array}{l}\text { Strategi } \\
\text { Pembelajaran }\end{array}$ & $\begin{array}{l}\text { a. Fungsi strategi } \\
\text { pembelajaran } \\
\text { b. Metode } \\
\text { pengajaran } \\
\text { c. Contoh metode } \\
\text { pengajaran: } \\
\text { penjelasan, dan } \\
\text { demonstrasi } \\
\text { melalui gambar- } \\
\text { gambar cerita. }\end{array}$ & $\begin{array}{l}\text { b. Peserta telah mamu membedakan } \\
\text { persiapan dan pemakaian dari jenis } \\
\text { media pembelajaran yang sesuai } \\
\text { dengan tematik pembelajaran } \\
\text { kepada siswa; } \\
\text { c. Peserta telah mampu menyebutkan } \\
\text { kelebihan dan kekurangan dari } \\
\text { masing-masing jenis media dengan } \\
\text { benar. } \\
\text { a. Peserta telah mampu menjelaskan } \\
\text { fungsi strategi pembelajaran dengan } \\
\text { online di masa COVID-19; } \\
\text { b. Peserta mampu menentukan metode } \\
\text { pembelajaran yang tepat sesuai } \\
\text { dengan tema pokok bahasan materi } \\
\text { kepada siswa; } \\
\text { c. Peserta mampu mendemonstrasikan } \\
\text { metode penjelasan, dan demonstrasi } \\
\text { materi secara tematik dengan } \\
\text { menggunakan media online seperti } \\
\text { zoom meeting dan whats app call } \\
\text { dan video call dengan siswa secara } \\
\text { atraktif, kreatif dan menyenangkan. }\end{array}$ \\
\hline
\end{tabular}

Sumber: data diolah, 2020
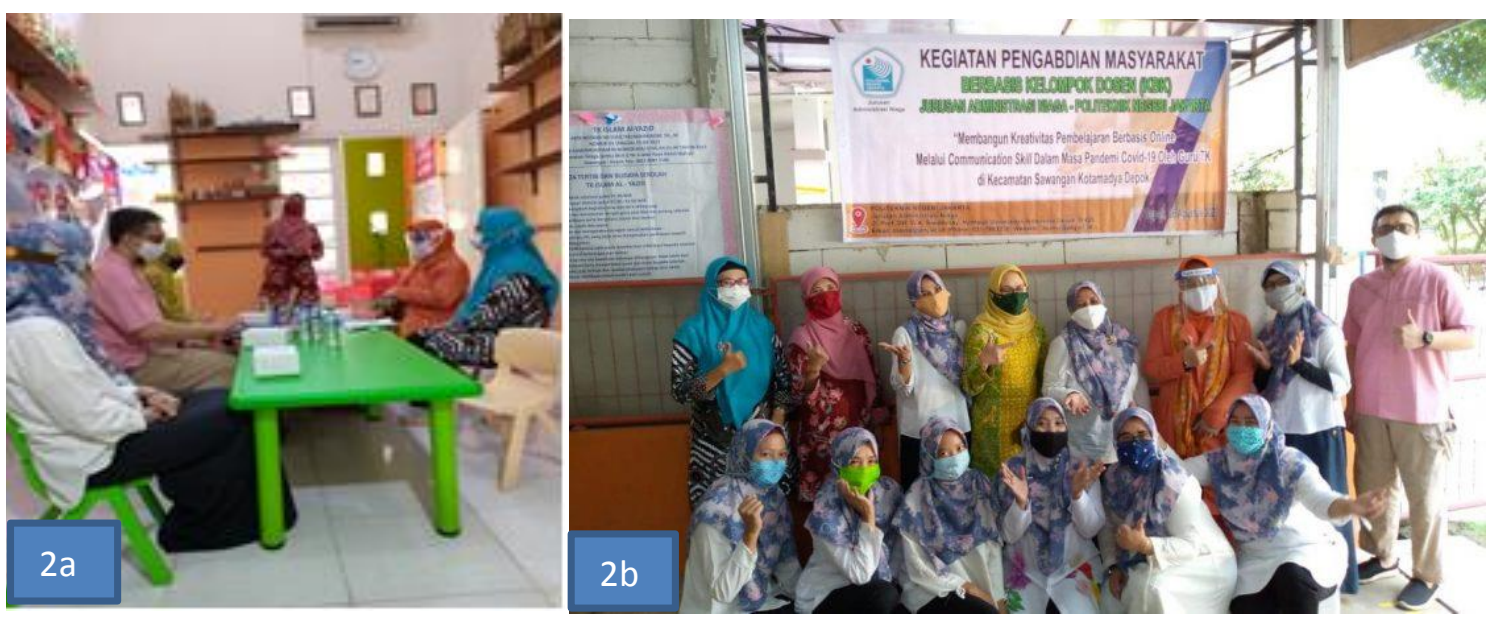

Gambar 2a. Foto kegiatan pelaksanaan pelatihan dan Gambar 2b. Foto bersama peserta pelatihan

Sumber: data diolah, 2020

Gambar 2, merupakan dokumentasi selama kegiatan pelaksanaan pelatihan, Gambar 2a, merupakan sesi diskui dengan guru-guru dan Gambar 2b, merupakan photo bersama untuk sesi penutup acara pengabdian. Merujuk pada teori komunikasi (Effendy, 2015), media pembelajaran (Kistner, 2015) dan strategi pembelajaran (Arsyad, 2014) yang menjadi rujukan dalam kegiatan pengabdian kepada masyarakat di TK Islam Al 
Yazid dan TK Aisyah Bustanul Atfhal 14, Sawangan, Depok menunjukkan bahwa keterampilan berkomunikasi yang dimiliki oleh Guru dan Kepala Sekolah di dalam proses pengajaran kepada siswa dan pertemuan dengan para orang tua siswa menjadi penting dengan memperhatikan lima factor menurut Laswell (sender, decoder, message, media,feedback) sehingga tidak terjadi kesalahan dalam menerima informasi.

Dampak dari pelatihan dalam pengabdian ini untuk media pembelajaran juga menjadi penting untuk dipertimbangkan dalam masa COVID-19 ini dimana pembelajaran pada saat ini (September 2020) masih menggunakan system pembelajaran dari rumah (school from home) dan adanya tatap muka secara langsung antara guru dan siswa dengan cara guru mengunjungi rumah siswa secara bergiliran dengan tetap memperhatikan protocol kesehatan. Metode pembelajaran dilakukan seperti penjelasan dan demonstrasi kepada siswa tentang materi yang diajarkan secara tematik. Adapaun media pembelajaran yang digunakan pada saat COVID-19 jika bertemu langsung menggunakan penjelasan materi yang diberikan, apabila pembelajaran dilakukan secara online maka digunakan media menggunakan video call antara siswa dengan guru dan zoom meeting diantara para guru dan orang tua siswa ketika ada kesulitan dalam menjelaskan materi kepada siswa. Bentuk penyajian materi yang digunakan dapat berupa power point dan juga gambar yang menarik dan menyenangkan. Kreativitas para guru dalam mengajar kepada siswa di era COVID-19 dituntut untuk lebih kreatif dan inovatif dengan tidak memberikan beban secara psikis kepada siswa yang sudah mulai bosan belajar di rumah.

\section{SIMPULAN}

Simpulan dan saran mengenai kegiatan pengabdian kepada masyarakat di TK Islam Al Yazid dan TK Aisysh Bustanul Afthal 14, Sawangan, Depok adalah bahwa komunikasi yang digunakan oleh para Guru dan Kepala Sekolah dalam mendukung pembelajaran dari rumah (school from home) menjadi perhatian penting agar tidak terjadi kesalahan persepsi dan komunikasi dengan siswa. Strategi pembelajaran digunakan dengan mempertimbangkan metode pengajaran yang tepat dan sesuai dengan materi yang diajarkan secara tematik melalui penjelasan dan demonstrasi menggunakan gambar yang menarik. Media yang digunakan guru selain tatap muka maka online digunakan video call dan zoom meeting dengan siswa. 


\section{UCAPAN TERIMA KASIH}

Penulis mengucapkan banyak terima kasih kepada UP2M-PNJ yang telah memberikan hibah dana pengabdian kepada masyarakat berbasis kelompok bidang keahlian/dosen tahun 2020, TK Islam Al Yazid, TK Aisyah Bustanul Afthal 14, Sawangan, Depok serta Ikatan Guru TK se-Depok yang telah menjadi mitra dalam kegiatan pengabdian kepada masyarakat tahun 2020.

\section{DAFTAR PUSTAKA}

Abdullah, Yudi dan Yetty Oktarina. (2017). Komunikasi Dalam Perspektif Teori Dan Praktik. Yogyajarta. Deepublis

Abidin, Yusuf Zainal. (2015). Manajemen Komunikasi: Filosofi, Konsep Dan Aplikasi. Bandung. CV. Pustaka Setia

Ahmadi, Farid. (2017). Guru SD Di Era Digital (Pendekatan, Media, Inovasi). Pilar Nusantara.

Azhar, Arsyad. (2014). Media Pembelajaran. Jakarta. PT. Raja Grafindo Persada.

Effendy, Onong Uchyana. 2015. Ilmu, Komunikasi Teori Dan Praktek Komunikasi. Bandung. Citra Aditia Bakti.

Fatkhurrokhman, Muhammad. Suroso Mukti Leksono, Sulaeman Deni Ramdani, Ikman Nur Rahman. (2018). Learning Strategies Of Productive Lesson At Vocational High School In Serang City. Jurnal Pendidikan Vokasi. Volume 8, No.2, June 2018 (163172). Online: http://journal.uny. ac.id/index.php/jpv

Kustandi, Cecep. (2011). Media Pembelajaran. Bogor: Ghalia Indonesia

Kistner, Saskia. Katrin Rakoczy, Barbara Otto, Eckhard Klieme \& Gerhard Buttner. 2015. Teaching Learning Strategies: The Role Of Instructional Context And Teacher Beliefs. Journal for Educational Research online 7 (2015) 1, S.176-197

Munir. (2013). Multimedia Konsep Dan Aplikasi Dalam Pendidikan. Bandung: Alfabeta

Pinter, A. (2011). Teaching Young Language Learners. New York. Oxford.

Shannon, Cad. (2018). Effective Management Communication Strategies. Walden University. https://scholarworks.waldenu.edu/dissertations.

Sukmahidayanti, Tanti. (2015). The Utilization Of Instructional Media In Teaching English To Young Learners (A Case Study Of An Elementary School Teacher In Bandung). Journal of English and Education 2015, 3(2), 90-100.

Sukiman. (2012). Pengembangan Media Pembelajaran. Yogyakarta. PT.Pustaka Insan Madani

Sudjana. (2000). Strategi Pembelajaran. Jakarta. PT.Raja Grafindo Persada.

Sugiyono. (2015). Metode Penelitian Kombinasi (Mix Methods). Bandung. Alfabeta 